\title{
RESEARCH ARTICLE \\ Neuritogenic Activities of Various Kappaphycus alvarezii Extracts in Hippocampal Neurons
}

Gabriel Tirtawijaya ${ }^{1}$, Maria Dyah Nur Meinita ${ }^{2,3 *}$, Md. Nazmul Haque ${ }^{4}$, and II Soo Moon ${ }^{5}$

\begin{abstract}
OPEN ACCESS
${ }^{1}$ Faculty of Biotechnology, University of Surabaya, Jalan Raya Kalirungkut Surabaya, Surabaya 60292, Indonesia

${ }^{2}$ Faculty of Fisheries and Marine Science, J enderal Soedirman University, Purwokerto 53123, Indonesia

${ }^{3}$ Center for Maritime Bioscience Studies, J enderal Soedirman University, Purwokerto 53123, Indonesia

${ }^{4}$ Department of Fisheries Biology and Genetics, Patuakhali Science and Technology University, Patuakhali-8602, Bangladesh

${ }^{5}$ Department of Anatomy, College of Medicine, Dongguk University, Gyeongju 38066, Republic of Korea

* Corresponding Author:

maria.meinita@unsoed.ac.id

Received: 7 January 2021

Accepted: 28 June 2021

Published: 18 August 2021

'Squalen Bulletin of Marine and Fisheries Postharvest and Biotechnology, 2021. Accreditation Number: 148/M/KPT/2020. ISSN: 2089-5690, e-ISSN: 2406-9272. doi: $10.15578 /$ squalen. 515
\end{abstract}

\begin{abstract}
The carrageenophyte Kappaphycus alvarezii seaweed is known to have neuritogenic activities. Post-harvest treatment of seaweed affects its biological activities. Five drying treatments of $K$. alvarezii, including oven-drying, sundrying, freeze-drying, shade-drying, and salting followed by shade-drying, were evaluated for their effects on neuritogenic activities. We also evaluated the neuritogenic activity of different parts of $K$. alvarezii thalli and its carrageenan waste. Neuron cells of the $19^{\text {th }}$ day pregnant rat fetuses were collected from the hippocampus by brain dissection. Neuron cells were isolated by dissociation of the hippocampal tissue. Cells were plated onto poly-DL-lysine-coated glass coverslips in 24-well plates and treated with extracts. All tested extracts were obtained from maceration using $95 \%$ ethanol. Freeze and shade-drying extracts exhibited significantly higher neuritogenic activities $(p<0.05)$ compared to that of the vehicle control. Carrageenan waste also significantly promoted the neuritogenic activities $(p<0.05)$ with an optimal dose at $1 \mu \mathrm{g} \mathrm{mL} \mathrm{m}^{-1}$. Old and young thalli showed insignificant differences in neuritogenic activities. The carrageenan waste extract retained neuritogenic activities. Thus, the utilization of carrageenan waste for neuritogenic material provides added value to the waste in the carrageenan industry. Freeze and shade dried $K$. alvarezii can be used as a neuritogenic agent to provide optimum biological activity.
\end{abstract}

Keywords: Hippocampal neurons, Kappaphycus alvarezii, Neuritogenic activity, Drying treatments, Carrageenan waste

\section{I ntroduction}

The carrageenophyte Kappaphycus alvarezii (formerly known as Eucheuma cottonii) is a member of Rhodophyta. K. alvarezii is a commercial seaweed and widely found in $11,109 \mathrm{~km}^{2}$ of cultivation areas in Indonesia (Mulyati \& Geldermann, 2017). K. alvarezii in Indonesia is classified into different strains based on their color phenotype, such as green, red, and yellowish-green. It has been reported that different strains produced different carrageenan yields (Zakaria., 2019). Risjani and Abidin (2020) identified two morphotypes, brown and green of $K$. alvarezii, from three areas in Indonesia that showed high similarity. The seaweed $K$. alvarezii is a rapidly growing seaweed, and its biomass can grow 4-7 times in 40 days (Kasim $\&$ Mustafa, 2017). The cultivation of $K$. alvarezii for carrageenan production has spread all across Indonesia due to its simple process. The production of carrageenophytes in Indonesia was 10.4 million tonnes in 2016, up by three percent from the previous year (FAO, 2018). K. alvarezii is well-known not only as a carrageenan source but also as a potential source of bioactive metabolites. Various bioactivities of $K$. alvarezii have been reported, i.e., antioxidant (Chakraborty \& Raola, 2017), anti-obesity (Wanyonyi, du Preez, Brown, Paul, \& Panchal, 2017), antidiabetic, and anti-inflammatory (Makkar \& Chakraborty, 2017), and neuritogenic (Tirtawijaya, Mohibbullah, Meinita, Moon, \& Hong, 2018) activities.

Some studies revealed that the bioactivity of seaweed extracts is affected by different thallus parts. The antimicrobial activity of Caulerpa species from the stolon part showed higher activity than those of the apical and basal parts (Freile-Pelegrin \& Morales, 2004). Stipes of Sargassum vulgarae exhibited higher antioxidant activity than that of the blades part 
(Arunkumar, Raj, Raja, \& Carvalho, 2021). The receptacle parts of Ascophyllum nodosum exhibited higher antioxidant activity than those of the others (basal, median, and apical). In contrast, S. muticum and Laminaria hyperborea showed no differences in antioxidant activity across the seaweed parts (Connan, Delisle, Deslandes, \& Gall, 2006). The thalli of $K$. alvarezii consist of the main thallus and branch (Fadilah, Alimuddin, Pong-Masak, Santoso, \& Parenrengi, 2016). The main thallus is older than the branches and has a larger diameter. To date, the different parts of $K$. alvarezii are rarely investigated for their biological activities. In Indonesia, commonly, the farmers use the whole part of $K$. alvarezii thalli.

Farmers dry the fresh seaweed thalli completely after harvest to reduce the water content and microbial growth. The post-harvest immediate drying of seaweed lengthens the storage, maintains their qualities, and facilitates the transportation process (Gupta, Cox, \& Abu-Ghannam, 2011). Sun-drying is the most common drying method in Indonesia due to its simplicity and low cost. Besides sun-drying, several common methods applied in seaweed drying treatments are freeze-drying, oven-drying, and shade-drying. Different drying methods have been known to affect the nutrient and phytochemical compositions of seaweed (Badmus, Taggart, \& Boyd, 2019; Silva, Abreu, Silva, \& Cardoso, 2019), and their antioxidant activities (Norra, Aminah, \& Suri, 2016; Amorim, Nardelli, \& Chow, 2020). Salting can preserve seaweeds for a short-term period, especially when they cannot be immediately dried due to weather conditions. The addition of high salt amounts creates osmotic conditions in the tissue that leads to the reduction of water content in seaweed (Gallagher, Turner, Adams, Dyer, \& Theodorou, 2016). According to Del Olmo, Picon, and Nunez (2019), salt preservation of $L$. ochroleuca prevented undesirable microbial contamination.

Natural sources of neuritogenic potential have been sought to develop new medication candidates to treat neurodegenerative diseases. Our previous studies reported that the $K$. alvarezii has potential neuritogenic activities by increasing the number of primary neurites, length of neurites (Tirtawijaya, Mohibbullah, Meinita, Moon, \& Hong, 2016), and axodendritic maturation (Tirtawijaya et al., 2018). Hence, we investigated the effect of drying treatments of this seaweed as a future neuritogenic agent source. Many studies showed that the bioactivities of the seaweed related to the drying treatments, but none have evaluated its neuritogenic activities. In the present study, the effects of five different drying treatments of $K$. alvarezii were evaluated for their neuritogenic activities. The treatments applied to $K$. alvarezii were as follows: ovendrying, sun-drying, freeze-drying, shade-drying, and pre-salted shade-drying.

$K$. alvarezii is known as the most common carrageenan-producing seaweed widely used in industries. Hence, we also observed the neuritogenic activity of carrageenan waste resulted from carrageenan extraction. During carrageenan separation, more than $15 \%$ of the raw materials become waste or residue. Several works have evaluated the carrageenan waste for bioethanol production (Meinita, Marhaeni, Jeong, \& Hong, 2019; Chong et al., 2020), but its bioactivity studies are still lacking. The utilization of carrageenan waste will increase its economic value. Thus, we also evaluated the neuritogenic activities of carrageenan waste to provide added value to it.

\section{Material and Methods}

\section{Chemicals}

Ethanol $95 \%$ for seaweed extraction was purchased from Samchun Chemical Co., Ltd (Seoul, Korea). The reagents for hippocampal neuron cell culture were supplied by Invitrogen (Carlsbad, CA, USA) and SigmaAldrich (St. Louis, USA). Trypsin inhibitor, poly-DLlysine, boric acid, glutamate, DMSO, ACS reagent 99.9\% and all other chemicals were of analytical grade and were acquired from Sigma-Aldrich (St. Louis, USA). Hank's balanced salt solution (HBSS), trypsin EDTA, $\beta$-mercaptoethanol, glutamax I, penicillinstreptomycin, B27- supplement, HEPES (1 M), sodium pyruvate, neurobasal medium, fetal bovine serum of analytical grade were purchased from Gibco, Invitrogen (New York, USA).

\section{Seaweed Materials}

Fresh thalli of brown color $K$. alvarezii were obtained from the Ternate farm, North Maluku, Indonesia, in August 2016. Thalli were rinsed twice in seawater followed by distilled water to remove debris and salt. After drying, tissues were ground using a grinder (HMF-340, Hanil Co., Seoul, Korea) and kept in the dark at room temperature (RT) for further use.

\section{Separation of Different Thalli Parts}

The thallus size of $K$. alvarezii ranged between 24 to $48 \mathrm{~cm}$. The branches were cartilaginous and pliable, ranging from 8 to $12 \mathrm{~cm}$ in length with unilateral to irregular branching types. The diameter of the branch was ranging from a few $\mathrm{mm}$ at the branch tips to greater than $1 \mathrm{~cm}$ in older tissues. We divided the thalli into two parts: the main stem and the new branches. The 


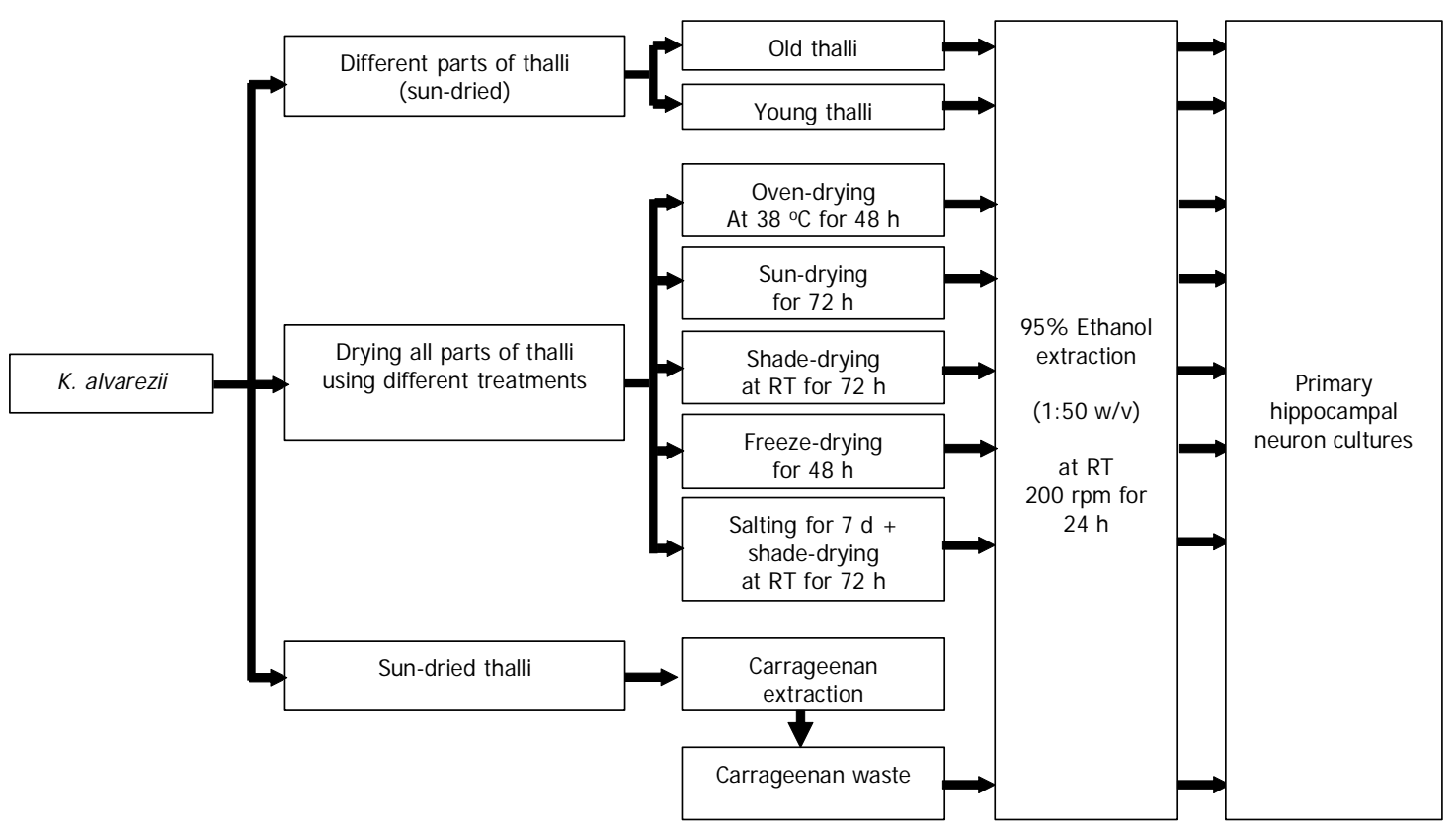

Figure 1. Schematic illustration of the experimental design in this study.

main stem was considered as the old thalli, and the new branches less than $5 \mathrm{~mm}$ diameter were considered as the young thalli (Figure 1). Both old and young thalli were sun-dried prior to grinding and extraction. Ethanolic extracts from each part were prepared using the procedure described in section of extract preparation.

\section{Drying Treatments}

After rinsing, $2 \mathrm{~kg}$ of whole fresh thalli were divided into five groups for drying treatments. Figure 1 shows the various drying treatments, including oven-drying at $38{ }^{\circ} \mathrm{C}$, sun-drying, freeze-drying, shade-drying, and salting, followed by shade-drying. Duration of drying treatments were $48 \mathrm{~h}$ for oven-drying, sun-drying, and freeze-drying, while that of shade-drying was $72 \mathrm{~h}$. The salting shade-drying treatment at RT was conducted using $30 \%(\mathrm{w} / \mathrm{w})$ dry salt of seaweed materials. After seven days, salted materials were rinsed with tap water three times and dried under shade for $72 \mathrm{~h}$. All the dried tissues were crushed into powder and extracted using $95 \%$ ethanol.

\section{Extract Preparation}

Five grams of seaweed powder was mixed with $95 \%$ ethanol $(1: 50 \mathrm{w} / \mathrm{v})$ and extracted in RT and was shaken at $200 \mathrm{rpm}$ for $24 \mathrm{~h}$. The extract was filtered using Advantec No.2 filter paper before being concentrated using an evaporator. Salt was removed from the extract by washing with $100 \%$ ethanol, followed by evaporation and $\mathrm{N}_{2}$ drying repeatedly. Dried extracts were concentrated to $8 \mathrm{mg} \mathrm{mL}^{-1}$ by DMSO and kept at $-20{ }^{\circ} \mathrm{C}$ in the dark-airtight vials for the next experiments.

\section{Carrageenan Waste Materials}

The carrageenan waste material was obtained from the sun-drying treated seaweed. Fresh thalli were used for carrageenan extraction. Thalli were sun-dried for $72 \mathrm{~h}$, and then $25 \mathrm{~g}$ of dried thalli were soaked in $1 \mathrm{~L}$ of distilled water. After soaking for $1 \mathrm{~h}$, tissues were pulverized into a pulp and mixed with $20 \mathrm{mM}$ calcium hydroxide solution (pH 9) by 1:50 (v/v). The extraction was performed in a shaking-water bath at $90{ }^{\circ} \mathrm{C}$ for 2 h (Manuhara, Praseptiangga, \& Riyanto, 2016). The solid materials (hereafter referred to as "carrageenan waste") were separated from the viscous filtrate by layered gauze. After filtration, the carrageenan waste was oven-dried at $60{ }^{\circ} \mathrm{C}$ overnight. Dried carrageenan waste was ground into a powder and extracted with 95\% ethanol, as mentioned previously. Extracts of carrageenan waste were tested in three different concentrations of 1,10 , and $20 \mu \mathrm{g} \mathrm{mL}^{-1}$.

\section{Primary Hippocampal Neuron Cultures and Treatments}

Primary cultures were observed in a 24 -well polystyrene plate. The isolation of hippocampal neurons and primary culture methods followed those of previous studies (Goslin, Asmussen, \& Banker, 1998; Hannan, Mohibbullah, Hong, \& Moon, 2017). The hippocampi were obtained from fetuses of 19-day pregnant rats (Sprague-Dawley) and dissociated to provide neuronal cells. Neuron cells were distributed onto poly-DL-lysine-coated glass coverslips in 24-well culture plates at a density of $1-2 \times 10^{4}$ cells $\mathrm{cm}^{-2}$. Neurobasal media (serum-free) with B27 supplementation were added into the culture plates. 
The plates were incubated under $95 \%$ air and $5 \% \mathrm{CO}_{2}$ at $37{ }^{\circ} \mathrm{C}$ for two days. Extracts of $K$. alvarezii at the concentration of $1 \mu \mathrm{g} \mathrm{mL}^{-1}$ from drying treatments and from different thallus parts were added to each culture media prior to cell plating. DMSO with a final concentration of less than $0.5 \%$ was used as vehicle control (Tirtawijaya et al., 2016).

\section{I mage Acquisition}

Images $(1,388 \times 1,039$ pixels $)$ were acquired from a Leica Research Microscope DM IRE2. The microscope was equipped with $\mathrm{I} 3 \mathrm{~S}, \mathrm{~N} 2.1 \mathrm{~S}$, and Y5 filter systems (Leica Microsystems AG, Wetzlar, Germany) and a high-resolution CoolSNAP ${ }^{\mathrm{TM}}$ CCD camera (Photometrics Inc., Munchen, Germany). The images were taken using Leica FW4000 program. The digital images were processed using Adobe Photoshop 7.0 software.

\section{I mage Analysis and Quantification}

The quantification and morphometric analysis of the neuron cells were observed with a software program from ImageJ, ver. 1.48 (http://imagej.nih.gov/ ij). Morphometric parameters were measured on the cells that were not intermingled with the processes of adjacent neurons. A minimum of 50 neuron cells were observed for morphometric analysis. The morphometric analysis included measurement of the number of primary neurites (NPN; neurites that originated directly from the soma), the total length of primary neurites (TLPN; a sum of the length of primary neurites), and the length of the longest neurite (LLN). The entire measured cell in extract-treated cultures was compared with vehicle control (cultures with DMSO) to evaluate the effect.

\section{Statistical Analysis}

Data obtained from at least three independent replications and showed as means \pm standard error (SE). Normal distribution data were evaluated by a Kolmogorov-Smirnov test prior to one-way analysis of variance (ANOVA). Post-hoc analysis for multiple comparisons of the experimental group's differences was analyzed at $p<0.05$ using the Duncan test. Statistical analysis was performed using the IBM SPSS statistic 23.0 software program (IBM Corp., USA).

\section{Results and Discussion}

Our current work evaluated the effects of $K$. alvarezii extracts on neuronal behavior. Accordingly, we observed the neurite outgrowth based on NPN, TLPN, and LLN in primary cultures of rat hippocampal neurons. In our previous study (Tirtawijaya et al., 2016), the ethanolic extracts from $K$. alvarezii showed high neuritogenic activities in developing hippocampal neurons at $1 \mu \mathrm{g} \mathrm{mL}^{-1}$. The development of neurites in neurons cells with many branches provides an extensive neuronal network (Hannan et al., 2019).

\section{Effects of Thallus Parts on Neuritogenic Activities}

Seaweed $K$. alvarezii thalli were divided into two parts; old and young thalli. The yield of the ethanol extract from old thalli (1.0\%) was higher than that of young thalli $(0.4 \%)$. Ethanolic extracts from each part were prepared and tested for neuritogenic activities. The activities of both old and young thalli were significantly higher compared to that of the vehicle control $(p<0.05)$. The old thalli exhibited insignificantly lower values of NPN, TLPN, and LLN $(3.7,11.7$, and $6.8 \%$, respectively) than those of young thalli (Table 1).

Meristem part of the brown seaweed Laminariales exhibited higher antibacterial activity than the blade and stipe parts (Vlachos, Critchley, \& Von Holy, 1999). More antibacterial compounds in meristem than in other seaweed parts might need to protect the meristem from microbial attack during growth and reproduction. The stolon part of Caulerpa, where the growth occurs, also exhibited higher antibacterial activity than those of basal and apical parts (Freile-Pelegrin \& Morales, 2004). Arunkumar et al. (2021) reported that stipe of Sargassum showed higher antioxidant activity compared to that of blade. This is probably because the first contained more alginate and fucoidan than the latter. Despite its higher yield, the old thalli comprised less neurotrophic compounds than the young thalli. $K$. alvarezii contained various kinds of neurotrophic compounds; most were secondary metabolites, such as phytosterol and oleic acid (Tirtawijaya et al., 2018). Thus, after considering both activity and yield, we decided to use the whole thalli of $K$. alvarezii for further experiments.

\section{Effects of Drying Treatments on Neuritogenic Activities}

The $K$. alvarezii is usually cultivated at the surface for $45 \mathrm{~d}$. Farmers commonly dry the thalli under the sun after harvesting. In this study, we dried fresh thalli by oven-drying, sun-drying, freeze-drying, shadedrying, and pre-salted, followed by shade-drying. Then, each dried thalli was measured for its changes in neuritogenic activities. The $K$. alvarezii extracts from various drying treatments showed neuritogenic effects compared to that of the vehicle control. The neuron 
cells in all drying treatments showed longer neurites, especially those of freeze- and shade-dryings. These extracts increased the number of branching neurites compared to those of the vehicle control (Figure 2). NPN values of $K$. alvarezii treated with different drying methods varied, ranging from 5.7 to 6.2 neurites per cell, with no significant differences between drying treatments. The freeze-drying treatment showed the highest yield (1.8\%) and NPN values (1.3-fold higher than control). On the other hand, salting followed by shade-drying revealed the lowest NPN values (1.2-fold higher than control). The number of neurites that originated directly from the soma is represented by the NPN value. Signal transmission between cells is dependent on neurites, so a high number of neurites enhances signal transmission between cells.

TLPN and LLN values showed significant differences between drying treatments $(p<0.05)$. The highest TLPN values was those of shade-drying and freeze-drying processes (1.6- and 1.6-fold, respectively, higher than control). LLN values showed that the shade-drying treatment was the highest (1.6-fold higher than control). The salting shade-drying extract had significantly lower activities on both TLPN and LLN compared to those of the other treatments (Table 2). In general, these results indicated that freeze-dried and shade-dried thalli had high neuritogenic activities. The structural formation of neurons depends on the neurite outgrowth (Poirazi \& Mel, 2001; Cao, Xu, Xu, \& Liu, 2005). The values of NPN, TLPN and LLN express the growth of neuron cells. Neuron cells require neurites (axon and dendrites) for signal transmission, whereas the high-branched neurites improve information reception from other neurons. The growing neurons form new connections, increasing neural activities (Houweling \& Ooyen, 2009). Therefore, the higher NPN, TLPN, and LLN values from the neuronal cell body, the higher possibility of neuronal connectivity formation. The morphology of dendrites is highly correlated to neuronal function (Tavosanis, 2012). On the contrary, the dendrites impairment is correlated to the defective nervous system (Mu \& Gage, 2011).

Freeze-drying and shade-drying treatments provided extracts with neuritogenic activities and optimum yield. Salting, oven, and sun-drying processes, involving heat and light exposures, decreased the neurotrophic activities, despite higher activities than that of control. Freeze-dried extract retained the highest yield (1.8\%) because freeze-drying preserves the nutritional components and qualities by preventing the fluid and solutes migration (Robic, Sassi, \& Lahaye, 2007). According to Charles, Sridhar, and Alamsjah (2020), the sun-dried $K$. alvarezii showed lower antioxidant activities than that of the oven-dried seaweed due to the lower contents of total phenolic and flavonoid. Antioxidant activities of the brown seaweed Himanthalia elongata decreased due to the high drying temperature that led to the reduction of total phenolic content (Gupta et al., 2011). Some brown seaweed extracts did not show significant differences in radical scavenging activities between freeze-drying and ovendrying at $40{ }^{\circ} \mathrm{C}$. Moreover, their activities decreased
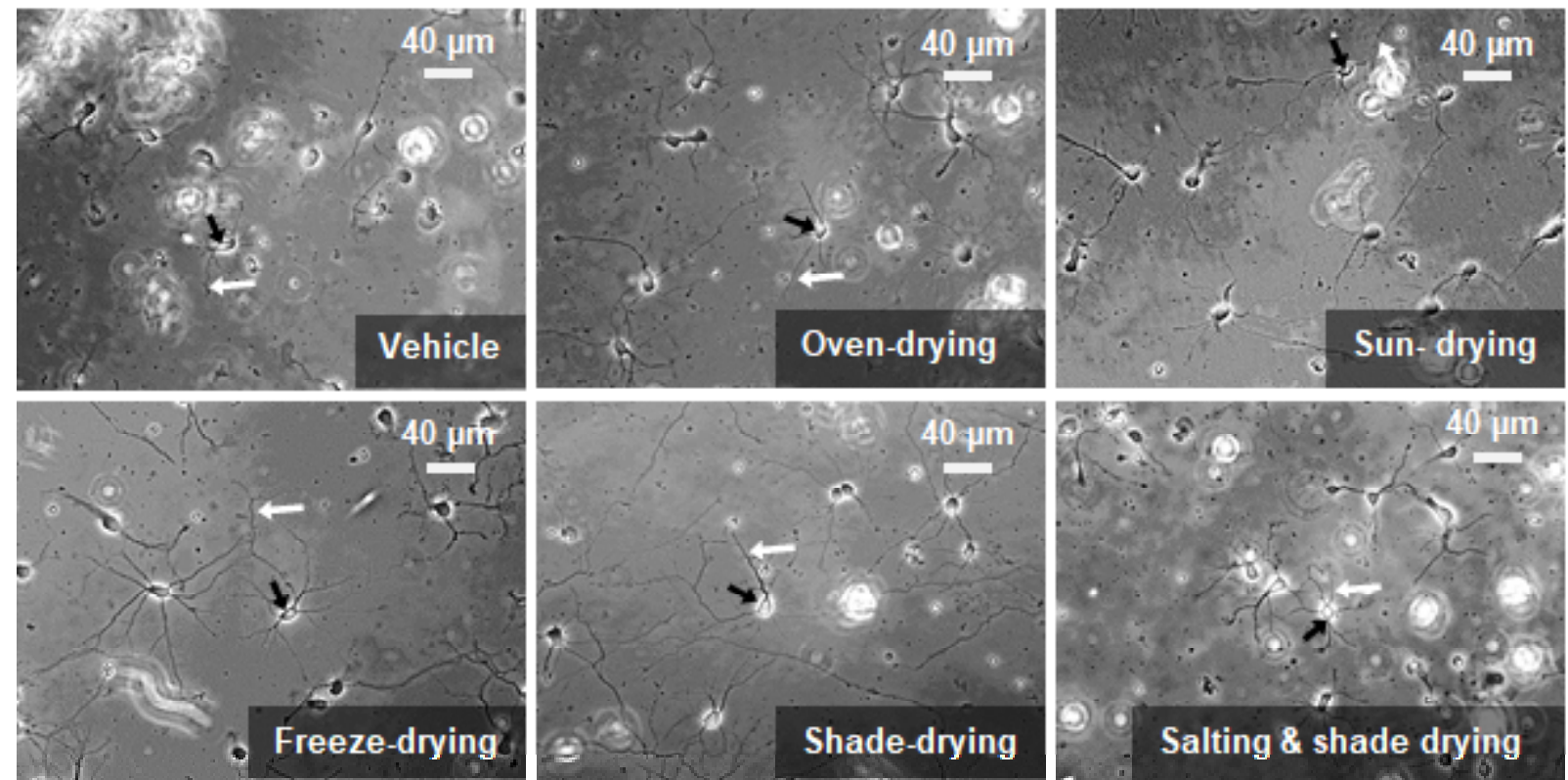

Figure 2. Representative phase-contrast photomicrographs of hippocampal neurons at 2 days of incubation. Neurons were cultured with vehicle (control) and ethanol extracts from $K$. alvarezii after different drying treatments. Grown neurites (white arrow) from the soma (black arrow) were evaluated for morphometric parameters. 
Table 1. Neuritogenic activities of different thallus parts after 2 days of incubation.

\begin{tabular}{lccc}
\hline \multicolumn{1}{c}{ Sample } & NPN & TLPN $(\boldsymbol{\mu m})$ & LLN $(\boldsymbol{\mu m})$ \\
\hline Vehicle & $4.1 \pm 0.2^{\mathrm{a}}$ & $118.4 \pm 7.3^{\mathrm{a}}$ & $44.0 \pm 1.9^{\mathrm{a}}$ \\
Old thalli & $5.4 \pm 0.2^{\mathrm{b}}$ & $162.34 \pm 7.6^{\mathrm{b}}$ & $65.3 \pm 4.7^{\mathrm{b}}$ \\
Young thalli & $5.6 \pm 0.2^{\mathrm{b}}$ & $181.41 \pm 8.2^{\mathrm{b}}$ & $69.7 \pm 3.0^{\mathrm{b}}$
\end{tabular}

Note: Values of the number of primary neurites (NPN), the total length of the primary neurites (TLPN) and the length of the longest neurite (LLN) are shown as means \pm SE. Different lowercase letters in each column indicate statistically significant differences between treatments, according to the Duncan test ( $p<$ $0.05)$.

Table 2. Neuritogenic activities of drying-treated $K$. alvarezii at 2 days of incubation.

\begin{tabular}{lcccc}
\hline \multicolumn{1}{c}{ Treatment } & $\begin{array}{c}\text { Yield } \\
(\%, \mathbf{w} / \mathbf{w} \text { DW })\end{array}$ & NPN & TLPN $(\boldsymbol{\mu m})$ & $\mathbf{L L N}(\boldsymbol{\mu m})$ \\
\hline Vehicle & - & $4.8 \pm 0.2^{\mathrm{a}}$ & $188.2 \pm 10.2^{\mathrm{a}}$ & $72.8 \pm 4.9^{\mathrm{a}}$ \\
Oven-drying & 01.04 & $5.9 \pm 0.2^{\mathrm{b}}$ & $283.3 \pm 13.1^{\mathrm{bc}}$ & $98.9 \pm 5.8^{\mathrm{bc}}$ \\
Sun-drying & 01.01 & $5.7 \pm 0.2^{\mathrm{b}}$ & $287.4 \pm 17.8^{\mathrm{bc}}$ & $106.8 \pm 6.9^{\mathrm{bc}}$ \\
Freeze- & 01.08 & $6.2 \pm 0.2^{\mathrm{b}}$ & $294.8 \pm 14.3^{\mathrm{c}}$ & $101.1 \pm 5.7^{\mathrm{bc}}$ \\
Shade-drying & 01.00 & $6.1 \pm 0.2^{\mathrm{b}}$ & $305.6 \pm 13.6^{\mathrm{c}}$ & $114.4 \pm 6.3^{\mathrm{c}}$ \\
Salting and & 01.01 & $5.8 \pm 0.2^{\mathrm{b}}$ & $248.4 \pm 10.6^{\mathrm{b}}$ & $89.1 \pm 5.3^{\mathrm{ab}}$ \\
shade-drying & & & & \\
\hline
\end{tabular}

Note: Values of the number of primary neurites (NPN), the total length of the primary neurites (TLPN) and the length of the longest neurite (LLN) are shown as means \pm SE. Different lowercase letters in each column indicate statistically significant differences between treatments, according to the Duncan test $(p<$ $0.05)$.

Table 3. Neuritogenic activities of carrageenan waste extract at 2 days of incubation.

\begin{tabular}{cccc}
\hline $\begin{array}{c}\text { Extract dose } \\
(\boldsymbol{\mu g} / \mathbf{m L})\end{array}$ & NPN & TLPN $(\boldsymbol{\mu m})$ & $\mathbf{L L N}(\boldsymbol{\mu m})$ \\
\hline Vehicle & $3.8 \pm 0.2 \mathrm{a}$ & $119.2 \pm 8.9 \mathrm{a}$ & $53.0 \pm 3.6 \mathrm{a}$ \\
1 & $6.1 \pm 0.1 \mathrm{~b}$ & $234.7 \pm 8.3 \mathrm{~b}$ & $90.6 \pm 5.7 \mathrm{~b}$ \\
10 & $5.9 \pm 0.3 \mathrm{~b}$ & $189.0 \pm 8.7 \mathrm{c}$ & $68.1 \pm 3.4 \mathrm{c}$ \\
20 & $5.9 \pm 0.3 \mathrm{~b}$ & $190.9 \pm 9.7 \mathrm{c}$ & $67.1 \pm 4.0 \mathrm{c}$ \\
\hline
\end{tabular}

Note: Values of the number of primary neurites (NPN), the total length of the primary neurites (TLPN) and the length of the longest neurite (LLN) are shown as means \pm SE. Different lowercase letters in each column indicate statistically significant differences between treatments, according to the Duncan test ( $p<$ $0.05)$.

significantly when the oven temperature was increased to $60{ }^{\circ} \mathrm{C}$ (Badmus et al., 2019).

The salting of $K$. alvarezii with $30 \% \mathrm{NaCl}$ induced osmotic pressure on the tissues that led to water removal. This condition might have caused the release of compounds responsible for neuritogenic activities from the tissue. Soufi, Romero, Motilva, Gaya, and
Louaileche (2016) reported that salting decreased the antioxidant activity of olive because of the loss of flavonoid compounds. Salting of Ulva rotundata with $25 \% \mathrm{NaCl}$ and storing at RT decreased the yield of ulvan extraction (Robic et al., 2007).

\section{Neuritogenic Activities of Carrageenan Wastes}

To evaluate the neuritogenic activities of carrageenan waste, we conducted carrageenan extraction according to Manuhara et al. (2016) procedure. Carrageenan is generally extracted from samples that have been dried under the sun. Sun-drying is the most common method used in the carrageenan industry. After carrageenan extraction, the remaining solid waste of $K$. alvarezii was separated from the viscous filtrate of carrageenan. The yield of the solid waste was approximately $15 \%$. The carrageenan waste exhibited significantly higher neuritogenic activities in neurons at $1 \mu \mathrm{g} \mathrm{mL}^{-1}$ than that of control $(p<0.05$; Table 3).

The addition of the waste extracts increased NPN, TLPN, and LLN by 1.6-, 2.0-, and 1.7-fold, respectively, compared to vehicle control. At concentrations of higher than $1 \mu \mathrm{g} \mathrm{mL} \mathrm{m}^{-1}$, the carrageenan waste extract did not increase NPN, TLPN, and LLN values. This condition suggested that the neuritogenic compounds in the carrageenan waste mediated the initial growth of neurites but inhibited neurites elongation at 10 and $20 \mu \mathrm{g} \mathrm{mL}^{-1}$. In future studies, the search of neuritogenic and neuroinhibitor compounds should be investigated. Comparing to the values of NPN, TLPN, and LLN (1.3-, 1.6-, and 1.4fold, respectively) from the $K$. alvarezi thalli (Tirtawijaya et al., 2016), this waste might retained most active compounds.

The remaining neuritogenic compounds in carrageenan waste still retained their bioactivities. Solid waste can be utilized as an alternative source for neuritogenic materials or the isolation of neuritogenic compounds. The global production of carrageenan in 2015 was 57,500 tonnes and has grown continuously 2-3\% annually (Porse \& Rudolph, 2017). The amount of carrageenan waste from semi-refined carrageenan extraction of $K$. alvarezii is about $23.5 \%$ (Roldán et al., 2017). Thus, the carrageenan waste globally was estimated up to 13,512 tonnes with an increase of 2$3 \%$ per year. Only a small proportion of the waste is used as fertilizer. Meanwhile, most of it is discarded to the environment, thus potentially creating pollution. In our previous study, we found that lipophilic compounds in $K$. alvarezii provide neuritogenic effects (Tirtawijaya et al., 2018). The isolated phytosterol from K. alvarezii increased NPN, TLPN, and LLN values and promoted 
spinogenesis and synaptogenesis of hippocampal neurons (Tirtawijaya et al., 2019). Nzekoue, Alesi, Vittori, Sagratini, and Caprioli (2020) reported that phytosterols demonstrate heat stability up to $96 \%$ at $85^{\circ} \mathrm{C}$ for $1 \mathrm{~h}$. Thus, it is assumed that the neuritogenic compounds in carrageenan waste were also lipophilic and were insoluble during the carrageenan extraction process. Uses of the carrageenan waste for neuritogenic sources may add value to the waste and reduce the pollutant risk.

\section{Conclusion}

This study demonstrated the effects of different parts of thalli and the drying treatments of $K$. alvarezii on neuritogenic activities. Different parts of thalli did not affect neuritogenic activities of $K$. alvarezii. Freezeand shade-dried $K$. alvarezii showed higher neuritogenic activities than those of the other treatments. Freeze-dried $K$. alvarezii also provided the highest yield $(1.8 \%)$. After carrageenan extraction process, we also found that carrageenan waste can be reused as a source of neuritogenic extract material. Further study is needed to identify neuritogenic active compound(s) in $K$. alvarezii and its carrageenan waste and to determine their stability.

\section{Acknowledgments}

This research was supported by the International Research Collaboration and International Publication (Basic Research) Grant, Ministry of Research, Technology, and Higher Education, Republic of Indonesia, Grant number: P/1726/UN23/14/PN/2019. This article is dedicated to Yong-Ki Hong, Professor of Biotechnology, Pukyong National University, Korea, on the occasion of his retirement and also as an appreciation for his work on seaweed biotechnology, including the neuritogenic activity of seaweed and its waste.

\section{References}

Amorim, A.M., Nardelli, A.E. \& Chow, F. (2020). Effects of drying processes on antioxidant properties and chemical constituents of four tropical macroalgae suitable as functional bioproducts. Journal of Applied Phycology 32, 1495-1509. doi:10.1007/s10811-020-02059-7.

Arunkumar, K., Raj, R., Raja, R., \& Carvalho, I. S. (2021). Brown seaweed as a source of anti-hyaluronidase compounds. South African Journal of Botany, 139, 470477. doi: 10.1016/j.sajb.2021.03.036.

Badmus, U. O., Taggart, M. A., \& Boyd, K. G. (2019). The effect of different drying methods on certain nutritionally important chemical constituents in edible brown seaweeds.
Journal of Applied Phycology, 31, 3883-3897. doi:10.1007/ s10811-019-01846-1.

Cao, D., Xue, R., Xu, J., \& Liu, Z. (2005). Effects of docosahexaenoic acid on the survival and neurite outgrowth of rat cortical neurons in primary cultures. Journal of Nutritional Biochemistry, 16, 538-546. doi:10.1016/ j.jnutbio.2005.02.002.

Chakraborty, K. \& Raola, V.K. (2017). In vitro bioactive analysis and antioxidant activity of two species of seaweeds from the Gulf of Mannar. Natural Product Research, 32(22), 2729-2734. doi: 10.1080/14786419.2017.1375923.

Charles, A. L., Sridhar, K., \& Alamsjah, M. A. (2020). Effect of drying techniques on color and bioactive potential of two commercial edible Indonesian seaweed cultivars. Journal of Applied Phycology, 32, 563-572. doi:10.1007/s10811-01901916-4.

Chong, T. Y., Cheah, S. A., Ong, C. T., Wong, L. Y., Goh, C. R., Tan, I. S., ..... Lim, S. (2020). Techno-economic evaluation of third-generation bioethanol production utilizing the macroalgae waste: A case study in Malaysia. Energy, 118491. doi:10.1016/j.energy.2020.118491.

Del Olmo, A., Picon, A., \& Nuñez, M. (2019). High pressure processing for the extension of Laminaria ochroleuca (kombu) shelf-life: A comparative study with seaweed salting and freezing. Innovative Food Science \& Emerging Technologies, 52, 420-428. doi:10.1016/j.ifset.2019.02.007.

Fadilah, S., Alimuddin, Pong-Masak, P. R., Santoso, J., \& Parenrengi, A. (2016). Growth, Morphology and Growth Related Hormone Level in Kappaphycus alvarezii Produced by Mass Selection in Gorontalo Waters, Indonesia. Hayati Journal of Biosciences, 23(1), 29-34. doi:10.1016/j.hjb. 2015.09.004.

FAO (Food and Agriculture Organization of the United Nations) [Internet]. 2018. FAO Global Aquaculture Production 19502016. [updated 2018; cited 2018 April 20]. Available from: http://www.fao.org/figis/servlet/SQServlet?file=/usr/local/ to m cat / 8.5.16/figis/webapps/figis/te m p/ hqp_2173690512948274130.xml\&outtype=html.

Freile-Pelegrin, Y. \& Morales, J. L. (2004). Antibacterial activity in marine algae from the coast of Yucatan, Mexico. Botanica Marina, 47(2), 140-146. doi:10.1515/BOT.2004.014.

Gallagher, J. A., Turner, L. B., Adams, J. M. M., Dyer, P. W., \& Theodorou, M. K. (2017). Dewatering treatments to increase dry matter content of the brown seaweed, kelp (Laminaria digitate ((Hudson) JV Lamouroux)). Bioresource Technology, 224, 662-669. doi:10.1016/j.biortech. 2016.11.091.

Goslin, K., Asmussen, H., \& Banker, G. (1998). Rat hippocampal neurons in low-density culture. In Banker G, Goslin K (Ed) Culturing Nerve Cells 2nd Edn, p. (pp 339-370). Massachusetts: MIT Press.

Houweling, A. R. \& Ooyen, A. V. (2009). Homeostasis at multiple spatial and temporal scales. In Squire, L. R. (Ed) New Encyclopedia of Neuroscience (pp 1189-1194). Cambridge, Massachusetts: Academic Press.

Gupta, S., Cox, S., \& Abu-Ghannam, N. (2011). Effect of different drying temperatures on the moisture and phytochemical constituents of edible Irish brown seaweed. LWT Food Science and Technology, 44(5), 1266-1272. doi:10.1016/ j.lwt.2010.12.022. 
Hannan, M. A., Haque, Md. N., Dash, R., Alam, M., \& Moon, I. S. (2019). 3b, 6b-dichloro-5-hydroxy-5a-cholestane facilitates neuronal development through modulating TrkA signaling regulated proteins in primary hippocampal neuron. Scientific Reports, 9, 18919. doi:10.1038/s41598-019-553648.

Hannan, M. A., Mohibbullah, M., Hong, Y. K., \& Moon, I. S. (2017). Proteomic analysis of the neurotrophic effects of Gelidium amansii in primary cultured neurons. Journal of Medicinal Food, 20(3), 279-287. doi:10.1089/ jmf.2016.3848.

Kasim, M. \& Mustafa, A. (2017). Comparison growth of Kappaphycus alvarezii (Rhodophyta, Solieriaceae) cultivation in floating cage and longline in Indonesia. Aquaculture Reports, 6, 49-55. doi:10.1016/ j.aqrep.2017.03.004.

Makkar, F. \& Chakraborty, K. (2017). Antidiabetic and antiinflammatory potential of sulphated polygalactans from red seaweeds Kappaphycus alvarezii and Gracilaria opuntia. International Journal of Food Properties, 20(6), 1326-1337. doi:10.1080/10942912.2016.1209216.

Manuhara, G. J., Praseptiangga, D., \& Riyanto, R. A. (2016). Extraction and characterization of refined k-carrageenan of red algae [Kappaphycus alvarezii (Doty ex P.C. Silva, 1996)] originated from Karimun Jawa Islands. Aquatic Procedia, 7 , 106-111. doi:10.1016/j.aqpro.2016.07.014.

Meinita, M. D. N., Marhaeni, B., Jeong, G. T., \& Hong, Y. K. (2019). Sequential acid and enzymatic hydrolysis of carrageenan solid waste for bioethanol production: a biorefinery approach. Journal of Applied Phycology, 31, 2507-2515. doi:10.1007/s10811-019-1755-8.

$\mathrm{Mu}$, Y. \& Gage, F. H. (2011). Adult hippocampal neurogenesis and its role in Alzheimer's disease. Molecular Neurodegeneration, 6, 85-94. doi:10.1186/1750-1326-6-85.

Mulyati, H. \& Geldermann, J. (2017). Managing risks in the Indonesian seaweed supply chain. Clean Technologies and Environmental Policy, 19, 175-189. doi:10.1007/s10098016-1219-7.

Norra, I., Aminah, A., \& Suri, R. (2016). Effects of drying methods, solvent extraction and particle size of Malaysian brown seaweed, Sargassum sp. on the total phenolic and free radical scavenging activity. International Food Research Journal, 23(4), 1558-1563.

Nzekoue, F. K., Alesi, A., Vittori, S., Sagratini, G., \& Caprioli, G. (2020). Development of a functional whey cheese (ricotta) enriched in phytosterols: Evaluation of the suitability of whey cheese matrix and processing for phytosterols supplementation. LWT Food Science and Technology, 110479. doi:10.1016/j.lwt.2020.110479.

Poirazi, P. \& Mel, B. W. (2001). Impact of active dendrites and structural plasticity on the memory capacity of neural tissue. Neuron, 29, 779-796. doi:10.1016/S0896-6273(01)002525.

Porse, H., \& Rudolph, B. (2017). The seaweed hydrocolloid industry: 2016 updates, requirements, and outlook. Journal of Applied Phycology, 29(5), 2187-2200. doi:10.1007/ s10811-017-1144-0.
Risjani, Y. \& Abidin, G. (2020). Genetic diversity and similarity between green and brown morphotypes of Kappaphycus alvarezii using RAPD. Journal of Applied Phycology, 32(4), 2253-2260. doi:org/10.1007/s10811-020-02223-z.

Robic, A., Sassi, J. F., Lahaye, M. (2007). Impact of stabilization treatments of the green seaweed Ulva rotundata (Chlorophyta) on the extraction yield, the physico-chemical and rheological properties of ulvan. Carbohydrate Polymers, 74(3), 344-352. doi:10.1016/j.carbpol.2008.02.020.

Roldán, I. U. M., Mitsuhara, A. T., Munhoz Desajacomo, J. P., de Oliveira, L. E., Gelli, V. C., Monti, R., .... Masarin, F. (2017). Chemical, structural, and ultrastructural analysis of waste from the carrageenan and sugar-bioethanol processes for future bioenergy generation. Biomass and Bioenergy, 107, 233-243. doi:10.1016/j.biombioe.2017.10.008.

Silva, A. F. R., Abreu, H., Silva, A. M. S., \& Cardoso, S. M. (2019). Effect of oven-drying on the recovery of valuable compounds from Ulva rigida, Gracilaria sp. and Fucus vesiculosus. Marine Drugs, 17(2):90. doi:10.3390/ md17020090.

Soufi, O., Romero, C., Motilva, M. J., Gaya, X. B., \& Louaileche, H. (2016). Effect of dry salting on flavonoid profile and antioxidant capacity of Algerian olive cultivars. Grasas $Y$ Aceites, 67(2), 1-9. doi:10.3989/gya.0641152.

Tavosanis, G. (2012). Dendritic structural plasticity. Developmental Neurobiology, 72, 73-86. doi: 10.1002/ dneu.20951.

Tirtawijaya, G., Haque, Md. N., Choi, J. S., Moon, I. S., Meinita, M. D. N., Choi, J. S., \& Hong, Y. K. (2019). Spinogenesis and synaptogenesis effects of the red seaweed Kappaphycus alvarezii and its isolated cholesterol on hippocampal neuron cultures. Preventive Nutrition and Food Science, 24(4), 418425. doi:10.3746/pnf.2019.24.4.418.

Tirtawijaya, G., Mohibbullah, M., Meinita, M. D. N., Moon, I. S., \& Hong, Y. K. (2018). The tropical carrageenophyte Kappaphycus alvarezii extract promotes axodendritic maturation of hippocampal neurons in primary culture. Journal of Applied Phycology, 30, 3233-3241. doi:10.1007/ s10811-018-1448-8.

Tirtawijaya, G., Mohibbullah, M., Meinita, M. D. N., Moon, I. S., \& Hong, Y. K. (2016). The ethanol extract of the rhodophyte Kappaphycus alvarezii promotes neurite outgrowth in hippocampal neurons. Journal of Applied Phycology, 28, 2515-2522. doi:10.1007/s10811-016-07956.

Vlachos, V., Critchley, A. T., \& Von Holy, A. (1999). Differential antibacterial activity of extracts from selected Southern African macroalgal thalli. Botanica Marina, 42(2), 165-173. doi:10.1515/BOT.1999.019.

Wanyonyi, S., du Preez, R., Brown, L., Paul, N.A., \& Panchal, S.K. (2017). Kappaphycus alvarezii as a food supplement prevents diet-induced metabolic syndrome in rats. Nutrients, 9(11), 1261-1271. doi:10.3390/nu9111261.

Zakaria, A., Rahman, E. N., Rahmani, U. N., Manurung, R., Puad, N. I. M., \& Abduh, M. Y. (2019). A production of carrageenan by different strains of Kappaphycus alvarezii cultivated in Serang, Indonesia. IIUM Engineering Journal, 20(2), 12-21. doi:10.31436/iiumej.v20i2.1062 